\title{
DAMAYANTI, DE VÍCTIMA A HEROÍNA $O$ UNA PRUEBA DE FIDELIDAD
}

\author{
Damayanti, from victim to heroine or proof of loyalty
}

\section{Sol Argüello Scriba*}

\section{RESUMEN}

Nala y Damayantī es una interpolación de la gran obra épica india el Mahābhārata, cuyo personaje principal es la heroína Damayantī. Sufre el destierro y los peligros de la selva inhóspita. Las descripciones de su belleza física muestran también su fortaleza espiritual y deberes de esposa, del suadharma, aspectos que la convierten en un modelo del estereotipo femenino de fidelidad en el Hinduismo.

Palabras clave: estereotipo femenino, belleza, épica, literatura.

\begin{abstract}
Nala and Damayantī is an interpolation of the great Indian epic Mahābhārata, whose main character is the heroine Damayantī.Suffers exile and the dangers of the inhospitable jungle. The descriptions of her physical beauty also show his spiritual strength and duties as a wife, the suadharma, aspects that makes her a feminine stereotype model of faithfulness in Hinduism.
\end{abstract}

Key Words: feminine stereotype, beauty, epics, literature.

Universidad de Costa Rica, Profesor, Escuela de Filología, Lingüística y Literatura. Costa Rica

Correo electrónico: solarcr1@gmail.com

Recepción: 14/05/2014. Aceptación: 26/09/2014. 


\section{Introducción}

Nala y Damayantī es una de la más conocidas narraciones interpoladas de amor, sufrimiento, separación y encuentro del Mahābhārata, obra clásica de la India y en lengua sánscrita, con más de doscientos mil versos a su haber, cuyos temas han continuado en obras teatrales, cine, cuentos y temas populares. El Mahābhārata permanece en la India hasta el día de hoy, no solo con sus divinidades o héroes y heroínas. Se podría hablar que está presente por medio de la gran tradición literaria, cultural y religiosa hindú permanente también en los estereotipos femeninos, modelos culturales del Hinduismo, entre ellos: Damayantī, el personaje femenino principal.

Es una narración interpolada con abundantes descripciones físicas de la naturaleza y de los personajes, no al estilo del género épico griego, o como se conoce en Occidente, donde abundan los epítetos épicos. Esta obra sí los presenta, pero de una forma muy característica, sus descripciones son abundantes y variadas, debido a la construcción sintáctica y gramatical del sánscrito en su etapa clásica. Largos párrafos descriptivos, abundantes de participios y palabras compuestas que permiten fluidez en la ambientación, aunque su traducción manifieste dificultades debido a las elipsis de verbos conjugados. A esto se le suma el origen oral de la composición, cuya creación dura en concluirse, según afirman los especialistas, unos nueve siglos. Aspecto que permite muchas interpolaciones.

En este trabajo, se estudia la presencia del cuerpo humano y su importancia en el desarrollo de la obra, donde se aprecia la unión entre belleza y fidelidad del personaje femenino Damayantī; por otro lado, la transformación de Nala que va desde su varonil hermosura hasta la deformidad física. Sus bellezas como pareja de héroes es comparable con la pareja primordial del Hinduismo: el dios y la diosa, complementarios y necesarios uno del otro. Las descripciones también hablan de la relación de Damayantī con la naturaleza y cómo se observa su belleza aún a pesar del abandono del esposo en la selva. Esa distinción por medio de las descripciones de ambos personajes, permiten distinguirlos de los otros personajes, los cuales son apenas descritos, a excepción de los dioses en el inicio de la obra.

Nala y Damayantī nos habla del recorrido de la pareja de esposos, quienes a pesar de que recorren un camino de abandono, distanciamiento y dolor, Damayantī es el personaje principal, la heroína que para llegar a serlo debe superar la etapa de víctima. Como personaje femenino difiere de los otros personajes femeninos del Mahābhärata. No solo cumple con los deberes de mujer, esposa, madre e hija, deberes impuestos por la ley y la religión, se caracteriza porque ama y es correspondida, pero su amor es transformador, a diferencia del de su marido Nala, que la ama pero no con la capacidad de entrega de ella.

Damayantī, al igual que las otras mujeres del Mahābhārata, vive en un mundo de guerreros, de envidias y ambiciones desmedidas, donde los dioses participan, no al modo de los dioses griegos en la Ilíada o la Odisea, sino ayudando a los piadosos y a los que los invocan. Sin embargo, la narración se da en la era de Kali, el dios de la destrucción, necesaria para la renovación y el establecimiento en un nuevo orden, esa es la mentalidad india que concibe la historia de manera circular, donde vida y muerte son parte de un parecido proceso.

Aunque el narrador habla que la divinidad Kali se ha posesionado de Nala y lo hace jugar compulsivamente, olvidando sus deberes como rey, esposo y padre, explica que se ha debido a que no cumplió con el ritual de purificación como lo exige la tradición, ya que Nala orina antes de la meditación vespertina y no se lava los pies, solo sus manos, lo que permite al dios Kali descender y posesionarse de él. El pensamiento indio permite que los dioses desciendan en las creaturas, ese es el verdadero significado de avatar de la raíz VRTT: descender. Según la obra, Nala, gracias a Kali, el personaje se vuelve egoísta y abandona a Damayantī a su suerte en plena selva, al hacerlo corta la mitad del sari, mientras duerme, para poder vestirse él, ya que los dados en forma de pájaros lo dejaron desnudo. 
La interpolación Nala y Damayantī al igual que el Mahābhārata manifiestan las características de la Kaliyuga (era de Kali), donde predomina la disputa, la envidia, la lucha por el poder y la pérdida de los valores éticos. La palabra kaliyuga proviene de kalaha, sustantivo derivado de kali, que significa tanto la destrucción como el tiempo, ya que éste todo lo destruye. También la palabra kala: tiempo, el que todo lo destruye. Los hindúes explican las cuatro eras de la vida, caracterizadas con la vaca, la cual parada sobre sus cuatro patas, representa la era de la perfección o la edad de oro de los griegos, en cambio en la edad del kaliyuga, la vaca está parada sobre una pata y al perder el equilibrio, comienza la crisis, después de ella se inicia una nueva era, que dura cientos de años en el sueño de Brahmā, el creador. Por ello los dioses y la creación participan de este proceso de destrucción y reconstrucción.

\section{La tradición épica india}

Para comprender la épica india, con más diferencias que igualdades con la épica griega, se debe ubicar histórica y geográficamente su desarrollo en la literatura sánscrita, cuyos modelos habían surgido de los Himnos Védicos en la India, en el segundo milenio a.C.

Laépica india es considerada una literatura religiosa y en sánscrito se le denomina Smriti, de la raíz SMAR: recordar, lo que se recuerda, también historia. Smriti es por excelencia los textos legales y éticos versificados, provenientes de los Dharma Sutras que se puede traducir como Dharma de la raíz DHŖ: lo correcto, lo establecido, el orden, al cual deben obedecer los seres humanos y los dioses. Otra de las ramas de la Smriti, es el compuesto Itihāsa de iti: así, ha: verdaderamente y āsa: lo que fue; término que convencionalmente se traduce como historia (Basham 1989: 69-70).

\section{El Mahābhārata}

Proviene de dos términos: Mahā: gran y de Bhārata, es el nombre de la tribu más importante de los indoeuropeos que llega a la India. Es la epopeya más antigua de la India y se podría ubicar el inicio de su composición en el siglo IV a.C., y su larga composición se termina más o menos 500 d.C. El tema central es legendario y se refiere a las luchas por el poder de una de las tribus de los Bhāratas, la tribu indoeuropea más importante en el subcontinente indio. Estas tribus se van desplazando y estableciendo primero en las regiones del río Hindus y posteriormente en el Ganges, región donde se desarrolla la obra. Compuesta por el autor legendario Vyasa, quien en la introducción explica cómo se la cuenta a su discípulo. Este largo poema nos muestra el desarrollo del Hinduismo.

Las tribus en conflicto son los Pāṇdavas o los hijos de Pandu, cuyo reinado se ubica en Indraprastha, cerca de la actual Nueva Dehli, y sus primos los Kauravas, hijos de Dhritarashtra, el ciego, quienes siempre han tenido envidia de sus posesiones, hasta de la esposa en común Draupadī. En un juego de dados, el hermano mayor de los Pandavas, Yudhisthira pierde todo hasta su esposa Draupadī, la cual es devuelta por orden del padre de los Kauravas. Los cinco hermanos junto con su esposa Draupadī van al exilio por trece años; y a su regreso se lleva a cabo la guerra que dura tan solo 18 días, al igual que los 18 capítulos del Mahābhārata. Mueren todos los que participan en la guerra, excepto los Pandavas; Yudhisthira se convierte en rey $y$ restablece el orden, al final de su reinado, cuando abdica, se dirige con hermanos y esposa hacia los Himalayas, donde se ubica el cielo.

\section{Nala y Damayanti}

Es una de las narraciones interpoladas del libro III, contada por el sabio y narrador Brihadaśva al héroe Yudhişthira quien se queja de la desgracia de su vida en el destierro. Esta pequeña interpolación de tan solo 26 breves capítulos narra las consecuencias del juego y la devoción de una esposa que salva del infortunio a su esposo y familia. La historia se da en un contexto completamente patriarcal y patrilineal, donde la mujer cumple, por tradición, un papel 
secundario, los héroes son varones guerreros, príncipes y reyes dueños de grandes extensiones de terreno, dueños además de las vidas de sus súbditos. Aún, en ese mundo, Damayantī, desde el inicio es única y a la vez igual a los demás personajes femeninos, es siempre la heroína y gracias a sus actos e inteligencia recupera todo lo perdido por el esposo como también a éste.

\section{La mujer-personaje en la épica india}

La posición de la mujer en la sociedad india, según nos dicen estos textos, estaba sometida al padre y a los hermanos, luego al esposo y demás miembros varones de la familia del marido. Los textos literarios hablan de que hubo poligamia, práctica que no se aprobaba en los libros de la ley. El padre entregaba en matrimonio a las hijas, éstas no podían ayudar, ni económica ni socialmente, a la familia del padre con un esposo exitoso, ya que en cuanto se casaban formaban parte de la familia del marido. La herencia, en la mayoría de los casos, pasaba de padre a hijo, aunque hubo sus excepciones en ausencia de hijos varones, se educaba a la niña como varón.

Por su lado, el matrimonio hindú tiene y tenía tres propósitos: la promoción de la religión, por medio de los sacrificios que realizaba el señor de la casa; la progenie, así el padre y sus ancestros se aseguraban una vida feliz después de la vida y la línea patrilineal continuaba. Aún se vive este propósito. Y en tercer lugar, la rati o el placer sexual para ambos cónyuges.

A pesar de que los textos de la ley, los Smritis, recomendaban que la edad ideal para que la jovencita se casara, era que ésta tuviese un tercio de la edad del novio, así si el varón tenía 24 años, ella debía tener 8 años. Aspecto que no contaba en la literatura clásica, ni en la vida real, esta costumbre se observó en la India, muchos siglos después. Por eso las heroínas de la literatura clásica o épica eran jóvenes no niñas. Además de que los eruditos, en la India antigua, afirmaban que los niños más fuertes nacían de las mujeres mayores de 16 años, y censuraban el matrimonio con niñas.
En cuanto a la ceremonia matrimonial era muy simple en épocas védicas; después en el Hinduismo, se elaboró con la finalidad de conservar su carácter sagrado, las razones para casarse eran religiosas y el matrimonio se convirtió en indisoluble. Los legisladores indios nombraban ocho clases de matrimonios religiosos, entre ellos el Gāndharva o matrimonio con el consentimiento de los dos, la mayoría de las veces era clandestino y muy frecuente en la literatura. Una versión de este matrimonio se denominaba el svayamvara o la escogencia propia que varias heroínas practicaron en el Mahābhārata. En esta obra, se aprecian varios estilos de svayamvara; uno, cuando se realizaba el concurso con el arco y la flecha, y el héroe ganador era escogido con el beneplácito de la jovencita, como se aprecia en la misma obra, cuando el héroe Arjuna gana a Draupadī. El otro, en la narración de Nala y Damayantī, cuando ella elige como esposo a Nala mucho antes de la presentación de príncipes y dioses que habían acudido al llamado de su padre Bhima, uno de los cinco hermanos Pandavas.

\section{Damayantī}

Damayantī, hija de Bhima, quien estaba casado con Draupadī, esposa compartida con sus cuatro hermanos: Yudhiş̧̧hira, Arjuna, y los gemelos Nakula y Sahadeva. Draupadī había practicado el svayamvara, y había escogido al arquero Arjuna, ganador entre todos los concursantes, entre ellos los cien primos Kauravas. Sin embargo, Kuntī la madre de los Pandavas, quien tenía el poder de conminar a los dioses con un mantra que le había dado un santón por sus devotas atenciones y que ningún otro personaje tiene en el Mahābhārata, por ese don escogió a los dioses con quién tener los hijos y además le pasó el mantra (oración) a la otra esposa de su cónyuge. Así nacieron los Pandavas, cada uno de un dios distinto. Kuntī no solo es respetada por ese don, sino que su palabra es considerada ley, tanto así que dispone que Draupadī sea la esposa de los cinco hermanos, quienes según la tradición y la ley 
de la poliandria, cada esposo debía convivir de dos a tres años con la esposa común y los otros esposos no debían acercarse a sus habitaciones, por eso se iban del reino y buscaban nuevas esposas. Así Bhima, uno de los hermanos, tiene otra esposa y con ella tiene los hijos que Draupadī, curiosamente, no tuvo con ninguno de los hermanos.

La historia de Nala y Damayantī sirve de apoyo para el destierro de los Pandavas, especialmente para Draupadī, quien debe sostenerse y demostrar fortaleza, a pesar de que es narrada para Yudhisthira.

El nacimiento de Damayantī es casi mágico, su padre Bhima, al no concebir hijos, realiza los sacrificios propicios y el vidente Damana le concede el don de tener hijos y así nacieron, según el texto: Damayantī, "una perla de niña" (p.36), palabra que denomina este personaje y es a su vez, un participio presente femenino de la raíz DAM: domesticar, domar, cuya forma en causativo significa: domar, domesticar y dividir, al igual que la raíz indoeuropea, cognada con el griego demos: pueblo y con el latín domus: casa, hogar. Significados paralelos al del sustantivo en sánscrito derivado de la raíz DAM, dama, que significa: hogar, casa (MacDonnell 1979:116). Luego los hermanos de Damayantī que apenas son nombrados: Damá, como adjetivo significa el que domina. El otro hermano es Damana que también es adjetivo y que también significa el que domina o el domador de caballos.

Los nombres de los hijos de Bhima, que significa el terrible, no se derivan de su nombre, sino del nombre del vidente Damana quien intervino para que obtuviese progenie. Llama la atención que Damayantī lleva el nombre del padre, en forma compuesta como epíteto, así bhīma-gā, nandinī, y bhīma-tā con el significado de la terrible, bhīma-putrikā: hija de Bhima, y dos interesantes epítetos bhavibhū o la que asume la forma de Damayantī y Bhima-sutā o la fuerza que guía. Apelativos que caracterizan su naturaleza de mujer fuerte. Así no solo es la que doma, sino también, la terrible. Estas cualidades junto con la perseverancia son las virtudes necesarias para constituir la fuerza de su dharma, lo que le permiten salir de víctima a heroína.

Por su lado, el nombre de Nala, rey de los Nishadas, hijo de Viraseña (el que controla el ejército) proviene de la raíz sánscrita NAL: oler, atar; como verbo causativo nalayati: hablar o brillar también, atar o aprisionar, confinar (Monier Williams 1960: 530), el sustantivo nala significa caña para el instrumento musical, también olor o perfume.

En cuanto a las descripciones físicas para Damayantī van desde lo más breve en un epíteto como la "la perla de niña" al comienzo de la obra, hasta volverlos más complejos especialmente, con los atributos físicos de su belleza, porque ella es un modelo o estereotipo femenino de mujer; y a su vez ayudan a comprender las vicisitudes del destierro: tres años, que le agregan suciedad, dolor, abandono, pero no le quitan esa permanente belleza; al contrario, entre más lejos del palacio o del hogar familiar, su belleza es más humana, más de mujer.

\section{La plenitud del amor}

Llegado el momento del matrimonio de Damayantī, su padre Bhima convoca a todos los reyes para que se lleve a cabo el svayanvara. La fama de belleza se había propagado por los confines de la tierra, pero también entre los dioses protectores védicos: Agni el dios del fuego, Indra: dios védico más importante, Yama: dios gemelo y psicopompo, Varuna: el que todo lo abarca, dioses que representan los cuatro elementos: fuego, aire, agua y tierra. Ellos acuden también al palacio. Todos son dioses védicos más importantes pero no en el Hinduismo. El texto la describe así:

Y Damayanti por su belleza, su esplendor, su dignidad, su fortuna y su atractivo, alcanzó gloria entre las gentes, la de bella cintura. A ella, llegada la juventud, un ciento de esclavas y otro de amigas, todas espléndidamente ataviadas, la seguían, como a Zaci. Allí la hija de Bhima, embellecida todos sus ornamentos, resplandecía en medio de sus amigas, la de miembros perfectos, como un relámpago. 
Bellísima, semejante a Shri la de los grandes ojos, ni entre los dioses ni entre los Yakshas había una hermosa semejante; y entre los hombres fue conocida entonces por primera vez una muchacha tal, turbadora del pensamiento de los mismos dioses, la hermosa (p.36, 37).

En este párrafo se aprecia la larga descripción introductoria, el cual resalta su aspecto físico, considerado una de las primeras cualidades que posee. Esta viene después de hablar de las breves cualidades que tienen sus hermanos, a quienes el narrador les dice: Dama, Danta y Damana el vigoroso, dotados de todas las virtudes, terribles, de terrible heroísmo (p.36). Y cuando el narrador termina con las cualidades de Damayantī, dice tan solo las siguientes palabras sobre Nala: Y Nala, tigre humano, incomparable entre las gentes sobre la tierra, era por su belleza el mismo Kandarpa en forma corpórea. (p.37) Kandarpa es uno de los epítetos de Kama el dios del amor. Ya desde un inicio los héroes masculinos son descritos con parquedad o con pocos términos, a diferencia de Damayantī, quien cada pormenor de su aspecto físico, como de la naturaleza que la rodea es detallado de manera constante en toda la obra. Lo que permite al narrador aclarar que ella es el personaje principal, aunque al inicio tratará la desgracia del rey Nala.

Como Nala y Damayantī, sin conocerse habían escuchado las cualidades de uno y del otro, en boca del cisne (hamsa en sánscrito), quien con sus palabras logra despertar el interés de Nala por conocerla y en Damayantī un enamoramiento tal que le afectará en su físico, tal como dice el texto:

\footnotetext{
Llena de pensamientos, triste, con el rostro pálido, delgada, estaba Damayanti, entregada a los suspiros; estaba Damayanti, entregada a los suspiros; con la mirada en lo alto, hundida en la meditación, tenía un aspecto de demente, pálido el color, penetrado de amor el corazón en un momento. No encuentra alivio en el sueño, la comida o los placeres del amor; ni de día ni de noche duerme; ;ay!, jay!, gime siempre. (p.39)
}

A diferencia de Nala, ella sufre el amor como enfermedad, como locura, se considera en la literatura clásica, que algunos personajes femeninos pierden la cordura con las circunstancias adversas, como también con el enamoramiento, esto es característico de la literatura romántica india, cuyos modelos se inician en la épica. En el caso de Damayantī, la demencia la pierde cuando escoge a su esposo y vive una vida feliz con él, y en las adversidades que comienzan con el destierro, ella manifiesta una lucidez y una fortaleza que diríamos viril, de ahí el epíteto de la terrible.

En la escogencia del esposo, ocurre la intervención divina, cuando convocados los reyes, sabios y dioses al svayamvara, Nala puede ver a Damayantīi, la cual sobresale entre las otras mujeres que la acompañan: ella la mejor de las mujeres, de miembros delicados, de fina cintura, de bellos ojos; parecía como si luciera el brillante resplandor de la luna. (p.44) Palabras preparatorias del ansiado encuentro entre los amantes, no sin antes la advertencia de Nala de que ha sido enviado por los dioses para que a pesar de oírlo, podrá escoger con libertad: Después de oírme, oh hermosa, decídete como desees. (p.44)

La escogencia de Nala por parte de Damayantī, después de la conversación con Nala, quien decidido a respetar a los dioses, insiste en que es su deber religioso primero que el humano y que debe escoger un dios por marido. Sin embargo, ella insiste en que lo quiere a él. Y cuando Nala se presenta ante los dioses, les explica que a petición de Damayantī deben estar todos juntos. Llegada la hora y el día propicios, según la tradición, Bhima llama a la corte a todos los pretendientes, estos son descritos así:

Los reyes penetraron en la gran sala brillante de columnas adornadas de oro, embellecida por una puerta de arco, como los grandes leones en la montaña. Allí los gobernantes de la tierra se sentaron en asientos varios, todos portadores de olorosas guirnaldas, con collares de piedras preciosas bien trabajadas. Se veían brazos robustos como gruesos barrotes de hierro, bellos, delicados, semejantes a serpientes de cinco cabezas. Las cabezas de los reyes, de bellos bucles, graciosas, de hermosa nariz, ojos y boca, brillaban como las estrellas en el cielo... (p.49). 
Y más adelante dice que en ese ambiente entra Damayantī, descrita así: la de rostro resplandeciente, y al entrar en la sala robó con su belleza los ojos y los corazones de los reyes. Sus miembros atrajeron la mirada de los magnánimos. (p.49) El narrador resalta las cualidades de Damayantī, su físico llama la atención, pero debe haber un contraste en la presentación de los pretendientes, quienes realmente a pesar de su resplandor, ella sobresale.

La abundancia de adorno, de belleza física de los pretendientes llama la atención de la heroína, pero su presencia sobresale puesto que utiliza el término robó la atención de los pretendientes, las contrastantes definiciones, entre la abundancia y la simplicidad provoca en el oyente la imagen visual de la joven Damayantī, la preparación de un clímax victorioso. Después de mirar a todos los pretendientes, tiene dudas de dónde se encuentra Nala, hasta que ve a un grupo de hombres hermosos y pide a la divinidad, haciendo el gesto de adoración que se manifiesten como son, y el narrador utiliza estos términos:

Ella vio a los sapientísimos todos, sin sudor, con los ojos fijos, con guirnaldas lozanas, sin polvo, sin tocar el suelo. Allí estaba el nisadha, doblado por la sombra, con las guirnaldas mustias, lleno de polvo y sudor, tocando el suelo y con ojos que guiñaban" (p.50)

Luego el texto dice que después del asombro, hombres y dioses bendicen la unión. Las divinidades le obsequian ocho regalos a Nala, entre ellos la capacidad de cocinar y disfrutar la comida, el cumplimiento del deber, y el nacimiento de hijos gemelos; sin embargo, a Damayantī no le dan nada, solo lo capacidad de tener hijos, con el tiempo engendró a Indraseno e Indrasena, la niña.

Aunque todo es alegría, en el capítulo VI, la historia retrocede al momento después de la elección de Damayantī y el narrador cuenta el arribo tardío del dios Kali, quien se entera por el dios Indra, que Nala, un ser humano, ha sido elegido por esposo. Se enoja tanto que le dice a Dvapara, su prolongación divina, que penetre los dedos de Nala. El dios Kali, es la disputa, su derivado es Kalaha: guerra y también Kala: es el tiempo, ya que en la mentalidad india, el tiempo todo lo destruye.

Kali decide apropiarse del cuerpo de Nala, quien, antes de la meditación de la tarde, no se lava los pies, y tampoco no hace el rito de purificación que se hace con la limpieza previa. Inmediatamente Puskara, hermano de Nala le pide que jueguen a los dados. Poseído por Kali es vencido en el juego, y pierde así sus posesiones. Damayantī interviene en varias ocasiones y no la escucha, por lo tanto dispone enviar a sus hijos a la casa de su padre Bhima, con el cochero de confianza.

\section{El destierro}

Nala va al destierro y Damayantī le sigue. Ya de camino Nala actúa injustamente con ell, puesto que en varias ocasiones le pide que lo abandone. El autor de la narración disculpa la actuación de Nala, porque culpa al dios Kali; sin embargo, hay una metáfora muy interesante cuando los dados se le presentan a Nala en forma de pájaros y se llevan su ropa, y éste al querer atraparlos, se convierten en dados, para el lector occidental es una imagen poética de cómo el jugador llega a perder todo. Pero para el grupo social al que pertenece Nala, el de los guerreros y príncipes, el de los dvijati o dvijatinan: los dos veces nacidos, el nacimiento natural y al del jati o casta, término que en sánscrito también significa pájaro; llama también la atención que los guerreros son los aficionados al juego, el que hace "volar" todas las posesiones, de la desgracia del jugador hay antecedentes en la literatura védica.

La imagen de Nala desnudo en la selva junto a Damayantī, rogándole que busque el Sur, donde se encuentran los grandes videntes (rishis), ruta que la llevará a donde los Vidarbhas, la familia paterna. A estas palabras le contesta Damayanti:

Se me estremece el corazón, me desfallecen los miembros todos al pensar, oh rey, una y otra vez, en tu intención. ¿Cómo me iría abandonándote en la selva solitaria, después de perder el reino, los bienes, 
atormentado por el hambre y la sed? En el bosque inmenso, oh gran rey, haré yo desaparecer la fatiga del cansado, del hambriento, del que añora aquella felicidad. No conocen los médicos una hierba medicinal para todos los dolores semejante a una esposa: te digo en verdad (p.51).

En el párrafo anterior Damayantī le dice a su consorte que aún con el dolor de estar en el exilio, ella lo acompañará pero más aún se compara con la medicina necesaria para el enfermo, ella no solo le ofrece compañía y liberación de su enfermedad. Recordemos que el oyente de esta historia es Yudhisthira, acompañado de Draupadī su esposa, la que pasará renegando y con deseos expresos de venganza, ha escogido el camino del destierro porque ese es su deber, Damayantī ofrece más que el deber a Nala, le sigue amando ya que le ofrece su sacrificio sin reclamos ni deseos de venganza. Pero siente desconfianza de las palabras de Nala, quien a pesar de asegurarle que no la abandonará, pero la engaña con estas palabras:

\section{Nala dijo:}

Así es como tú dices, oh Damayanti la de la bella cintura: no hay amigo como una esposa, medicina del hombre afligido. No tengo deseo de abandonarte. ¿Por qué, oh tímida, dudas? Me reprocharía a mí mismo antes que a ti, oh irreprochable (p.62-63).

Entonces Damayantī dudosa le pregunta:

¿Sí, oh gran rey, no deseas separte de mí, por qué me señalas los caminos de los vidarbhas? Y hablas sin cesar del camino de mi casa, oh el mejor de los hombres; con ello crece mi dolor, oh semejante a los inmortales. Y si tus intenciones te conducen a tus parientes, juntos los dos marcharemos a los vidarbhas, si lo deseas. El rey de los vidarbhas te honrará, oh hombre sin orgullo; allí, honrado por el rey, vivirías feliz en nuestra casa (p.62-63).

Nala no solo le provoca dolor porque la está engañando, sino también la somete al abandono y la deja media desnuda en el bosque, la hace víctima de la pérdida de su honor, así por segunda vez, las palabras de Damayanti no son importantes. Al entrar en una choza abandonada y mientras duerme Damayantī, Nala se repite a sí mismo su desgracia y decide abandonarla después de cortar el sari por la mitad. Sale huyendo, regresa llorando y le dice estas palabras:

Cortado su vestido, cómo estará, como loca, cuando se despierte la de bellas caderas? ¿Cómo sola, la hija de Bhima, abandonada por mí, la esplendente, marchará por la selva inmensa, poblada de fieras y serpientes? (p.66).

Después de pedirle a los dioses que la protegen afirma: ;Tu virtud te protege!, el traductor Rodríguez Adrados, utiliza el término virtud concepto referido a la cualidad y fortaleza que tiene el vir, lat. Varón; lo correcto y que nos traducible es el concepto del dharma, entendido aquí como la que cumple con sus deberes de esposa, la fiel en cualquier momento. Según el matrimonio hindú, ambos esposos prometen seguirse mutuamente, mientras uno sigue al otro, sin pretender el dominio uno del otro, y entre lo prometido está la fidelidad en la enfermedad y la desgracia. Nala ha roto la promesa aunque el autor le echa la culpa en todo momento al dios Kali dentro de él; a pesar de esto, Nala reconoce que Damayantī no es capaz de romper su promesa y esa fortaleza moral será su protección. Aquí en la desgracia de Damayantīi, en su situación de víctima es cuando va a surgir la verdadera heroína.

Cuando se despierta abandonada grita llorando:

¡Gran rey! ¿Oh señor, oh gran rey, oh dueño, por qué me abandonas? ¡Oh!, estoy muerta, estoy perdida, estoy atemorizada en la selva desierta. En verdad, oh gran rey, eres conocedor del deber, verídico. ¿Cómo, diciendo: "así es la verdad” te has ido dejándome dormida? ¿Cómo te has ido abandonando a tu esposa, excelente, fiel, si sobre todo no te he ofendido con alguna ofensa en que interviniera otro hombre? Debes hacer reales para mí aquellas palabras, oh el mejor de los hombres, que dijiste un tiempo en presencia de los guardianes del mundo (p.68).

Con estas palabras le recuerda el deber, el dharma de esposo, la supuesta verdad, los dioses no mienten, en la tradición india, el esposo es el dios de la esposa, a imagen del deva y la devī, los dioses hindúes no se encuentran solos, tienen esposa, aunque no 
tengan hijos el dharma los obliga, al igual que a los seres humanos, a cumplir con sus deberes. La ha engañado porque le ha mentido y recuerda también la promesa dada a ella y donde los dioses-guardianes del mundo eran testigos. Damayantī puede reclamar porque ha sido fiel, no ha cometido adulterio, su palabra es una verdad moral, así es doblemente heroína.

Dayamantī a partir del capítulo XI se encuentra víctima del abandono, es cuando las descripciones de ella son más efusivas con respecto a su cuerpo, nunca deja de ser bella a pesar de que no puede ni bañarse, el baño es importantísimo en el Hinduismo, es parte del ritual, no puede arreglar sus cabellos ni cambiar de atuendo, está sola a merced de cualquier fiera. Es cuando maldice a quien tenga aprisionado a su esposo, cuando dice:

Que aquel por cuya maldición halla el dolor el dolorido nisadha, tenga un dolor superior a nuestro dolor. El malvado que ha obrado así con Nala, cuya mente no tiene maldad, viva una vida sin felicidad, alcanzando un dolor mayor que el suyo.( p.70)

Y mientras deambula por el bosque una boa gigante la aprisiona y ella no puede hacer nada más que gritar, mientras tanto piensa en Nala y en el sufrimiento de él. Llega el cazador y mata la serpiente: Una vez libertada, el cazador la lavó con agua y después de darle comida, consolándola, la preguntó oh bharata: ¿De quién eres hija, la de los ojos de gacela joven? ¿Cómo has entrado en el bosque? ¿Cómo has llegado a esta gran miseria, mujer? Damayanti le cuenta lo sucedido. Se observa en el texto, cuán importante es lavarse primero antes de la comida. Sin embargo, el cazador la observa con ojos de hombre y deseoso de estar con ella, tal como el texto lo dice:

Y el cazador, al verla cubierta solo con medio vestido, con opulentos muslos y pechos, con miembros delicados, irreprochables, con ojos provistos de curvas cejas, con voz tan suave, entro en la obediencia del amor. El cazador, con blanda voz, delicadamente, procuraba hacerse agradable, lleno de amor: la ilustre lo comprendió.

Damayanti, al comprender a aquel malvado, la fiel al marido, llena de una cólera violenta, se inflamó en su espíritu. El malvado, el vil, anhelante de ultrajarla, comprendió que era difícil de ultrajarla, ella que ardía como una llama. Damayanti, dolorida, privada del esposo y del reino, pasada la ocasión de las palabras, le maldijo, airada: "Cómo yo no pienso en mi espíritu en otro distinto del nisadha, así caiga muerto este vil cazador.

Con solo pronunciar la palabra, el cazador, como un árbol quemado por el fuego, cayó muerto sobre la tierra (p.71).

La cita anterior llama la atención porque el narrador presenta la inmediata condición de desamparo de la heroína; la boa constrictora que la está matando; el cazador que la salva pero luego decide ante su belleza y media desnudez, abusar de ella. El texto elige un cazador, pudo haber escogido un héroe, pero no lo hizo porque un héroe la hubiera llevado al hogar paterno y su camino de heroína se hubiera acabado aquí y aún le falta vencer otras pruebas. Ha salido victoriosa en dos. Otro aspecto que llama la atención en el texto, el cual pareciera que transmite una enseñanza práctica: las mujeres en la selva no se pueden defender por su condición de mujeres. Mas llama la atención que el don de la palabra es lo que protege a Damayantī de ambos peligros, debido a su fuerza moral, porque ella afirma que solo su esposo le interesa, antes de fulminar al cazador con su maldición, lo que le da el dharma o fuerza moral suficiente. La máxima moral se derivaría más bien de pensar, hablar y decir la verdad, valores que hacen al ser humano fuerte, la sociedad india le da mayor valor a esto.

Por otro lado, presenta el modo en que su belleza física, antes valorada en el palacio, en la selva, en el abandono la convierte en víctima de un posible abuso sexual, más bien su aspecto físico es, por primera vez, descrito sexualmente y de manera seductora, en las descripciones anteriores solo eran insinuaciones de su femineidad, cuando se dice que tenía una hermosa cintura o amplias caderas, ahora lo tiene todo para ser deseada como una mujer que ha perdido su status y es vulnerable, ya que el cazador está fuera de los grupos sociales hindúes, pertenece a un grupo no ario, no es hindú. El texto manifiesta una diferenciación social. 
El texto nos manifiesta la vulnerabilidad de su abandono. En el capítulo XII, Damayanti se interna en la selva y son descritos los animales depredadores pero sobresale la inmensidad de flora, además de los habitantes de una etnia prearia los mlechas, que hablaban una lengua distinta al sánscrito o a los prácritos. Las seres fantásticos llamados Nagas o serpientes que hablan y los Rakshashas seres de fuerza inconmensurable que raptaban mujeres.

Esta descripción detallada de los peligros y naturaleza fabulosa, el narrador dice de Damayanti: Con su esplendor, su dignidad, su belleza, la vidarbha marcha sola buscando a Nala; y a nadie temía la hija de Bhima, la esposa del rey, internada en la selva despiadada, atormentada por la desgracia de su esposo. (p.74-75) El ambiente descrito contrasta, sirve de telón para la fortaleza interior de Damayanti, ya no siente miedo solo piensa en la desgracia de su esposo. Parece contradictorio, no busca salvarse a sí misma, solo piensa en su amado; aunque el texto presenta más adelante los reclamos que ella le hace a Nala cuando dice:

\footnotetext{
¿Por qué no me hablas? Me devora esa aparición terrible, funesta, con las fauces abiertas, el rey de la selva, hambriento; $i$ por qué no me salvas? "No amo a otra mujer que no seas tú". Así hablabas siempre. Haz verdadera, hermoso, esa palabra dicha en un tiempo, ¡oh rey! A mí, tu amada, tu esposa, loca deshecha en lamentos, oh rey de hombres, el querido a la querida, ¿por qué no me hablas? De la extenuada, mísera, pálida, sucia, oh señor de la que encierra tesoros, de la que se cumbre con medio vestido, de la solitaria que gime sin protección, como una gacela de grandes ojos extraviada de sus padres, no te acuerdas, oh venerable, de la que llora, oh destructor de enemigos. ¡Oh gran rey! En la gran selva, yo, sola, Damayanti, te hablo; ¿por qué no me respondes? (p.75-76).
}

En este largo párrafo, imaginariamente conversa con el león que se le acerca como si fuese Nala, llamado con el epíteto tigre de hombres. Ella misma describe su apariencia, degradada por el abandono y su reclamo concluye con el por qué no me respondes, más adelante sigue narrando cómo se acerca al tigre, para que la libere de su aflicción, es el intento de suicidio. Aquí, Damayantī habla al tigre como si fuera a su esposo y el párrafo concluye: Al oír en la selva mi lamentación, este rey de las fieras, de su propio impulso, se va a ese curso de agua, de clara corriente, que va hacia el mar. (p.76) Así termina el lamento de Damayanti, su intervención, al igual que Nala, el tigre la abandona.

El lamento de Damayantī continúa como un monólogo donde alucina, pero enumera los nombres de plantas y árboles, la naturaleza está allí a su lado, inmensa, avasalladora. Conversa con la montaña, y le dice: la mejor de las montañas (p.77) y le cuenta que es hija de Bhima el héroe, su suegro Virasena y luego sigue con la descripción de la grandeza de Nala, y le reclama. Posteriormente el texto dice que Damayantī ha caminado tres días y tres noches, tiene una visión, donde los ascetas del bosque le garantizan la recuperación del esposo, hijos y reino. En este momento, la descripción física es distinta, la hace el narrador y afirma:

Vio el bosque apacible habitado por los ascetas, poblado de toda clase de bestias, lleno de tropas de monos y con numerosos ascetas; y al verlos recobró ánimo, la de bellas cejas, bella cabellera, bellos muslos, bellos pechos, bellos dientes, la resplandeciente, la de los bellos pies y bellos ojos, grandes y negros. Y entró en el bosque de los ascetas la amante del hijo de Virasena, la perla de las mujeres, la ilustre, Damayanti la atormentada (p.79).

El texto sigue narrando, cómo es interrogada por los ascetas, quienes le preguntan si es diosa por su belleza física, a lo que contesta que ella es humana. Y les cuenta sobre Nala, dando sus cualidades de valentía y belleza. Ellos contestan que llegarán a reunirse y a recuperar todo.

La descripción que el narrador hace es difiere de la hecha por ella o cómo la vio el cazador. En esta ocasión, la belleza es detallada con las cualidades físicas femeninas iguales a las de una diosa. El medio es distinto, el interlocutor ha cambiado, la naturaleza no la daña, el cazador tampoco, los ascetas la ayudan, su camino de heroína, a pesar de los peligros continúa bien, porque ella tiene la fuerza moral, el dharma o deber moral, el de esposa devota. Hay ayuda de fuerzas espirituales superiores, porque ella 
se lo merece por su grandeza física también, es mujer y como tal es bella, es la encarnación de la diosa, es un modelo a seguir. Ante los ojos humanos está físicamente abandonada, ante los ojos de los que han logrado una etapa espiritual superior, como los ascetas, su belleza resalta. Así el oyente-lector conoce la transformación física que habla de belleza y no de deterioro.

Después de la visión de los ascetas, creyendo que es solo un espejismo continúa su camino y le pregunta a un árbol de ashoka, o el árbol-dolor, expresión del diálogo consigo misma. En ese momento, se encuentra con una caravana, y el texto narra: Al ver la gran caravana, la gloriosa esposa de Nala se acercó, la de bellas caderas, y penetró en medio de los hombres, como loca, llena de dolor, cubierta con medio vestido, delgada, pálida, sucia, con el cabello polvoriento. (p.82). El narrador la describe tal como podría estar una mujer en la selva, desamparada, sucia, sin cordura y semidesnuda. Les pregunta por Nala, pero no hay una respuesta positiva. Son mercaderes y le dicen hacia dónde se dirigen. Es acogida en la caravana y durante la noche, una manada de elefantes salvajes ataca sin consideración, destrozando la caravana. Es culpada por tal hecho, el texto narra:

La mujer que hoy entró en la caravana de aspecto demente, desarreglada en toda su persona, pero de belleza humana, ha realizado esta terrible obra de magia; es una Rakshashi o Yaksi sin duda, o Pizaci provocadora de miedo, de ésta es todo este mal, no hay que dudarlo. Si veo a esa malvada, asesina de la caravana, causante de mil dolores, con bolas de tierra y hasta con arena, con cañas y con leños, con los puños, la mataré sin piedad, a ella, la maga de la caravana (p.87).

Nuevamente, el aspecto físico de locura y poco arreglo, pero aún bella, provoca una mala impresión y lo que fue un simple acto de la naturaleza, la furia de los elefantes, se convierte en un acto de superstición. Ella se pregunta qué mal ha cometido, y se dice: Sin duda ha obrado un gran pecado que debo haber cometido en una vida anterior. (p.88) Esta participación de Damayanti, como resultado de la desgracia máxima que pudo haberle ocurrido, la respuesta que se da a sí misma se refiere a la idea que ya está presente en el Hinduismo: la rencarnación.

Después de caminar lamentándose de aunque no se acuerde de haber actuado mal, está recibiendo la recompensa de sus actos, este es la noción del karma. Llega a una gran ciudad donde es acogida por los reyes y permanece allí. La madre del rey, dice que a pesar de que parece una loca se observa una belleza divina. La invita a vivir en su palacio a lo cual ella acepta estar como una viuda, pero no comerá los restos de la comida, como los śudras, la casta más baja entre los hindúes, ni se lavará los pies, esto en señal de duelo. La viuda perdía su status social, que era otorgado por el esposo, en ausencia de éste, muchas veces era rebajada a sudra.

A partir del momento en que Damayantī es abandonada por su esposo, ya no se valora por ser la hija y esposa de héroes, sino como mujer, unas veces por la belleza de mujer joven y otras por su abandono físico. Está vulnerable a cualquier situación peligrosa que le pueda suceder por ser mujer y bella, pero ahora en el palacio se encuentra protegida.

A partir del capítulo XIV, Nala aparece, en el momento inmediato al abandono de Damayantī. Ve un incendio y en medio del fuego ve al rey de los Nagas (culebras) y lo rescata, quien, bajo engaño, lo muerde y le inyecta el veneno que le duele al dios Kali, mas no a Nala. Pero al ser mordido, lo convierte en un hombre de brazos cortos o enano. El enano representa la ignorancia en el Hinduismo, pero en forma de enano el dios Vishnu salva la tierra. Nala llega a la tierra del rey Rituparna, disfrazado de cocinero y como un experto en caballos, dones otorgados por uno de los dioses, el día de su boda. El nombre que adopta es Vahuka.

En los capítulos XIV y XV el narrador regresa al momento inmediato en que salen Nala y Damayantī al destierro. En el XV, cuenta como Bhima manda a buscar a su hija, ofrece una gran recompensa al brahmán que la lleve a su palacio. Así se da, no está buscando a Nala, busca a su hija por motivos obvios, una mujer sola y en plena selva donde los peligros la acechan.

El brahmán la encuentra en el palacio donde la madre del rey le había dado refugio, 
el narrador emplea una técnica moderna de narración el llamado flash back, de esta manera cubre todos los sucesos de ambos personajes, los empieza a reunir, creando la expectativa del momento culminante.

Pero en ese "descubrir"a Damayantī el narrador cuenta:

Cuando vió a aquella mujer de grandes ojos, extremadamente sucia y delgada, pensó: Es la hija de Bhima", conjeturándolo por sus señales: "Esta mujer tiene igual apariencia que aquella que conozco. He logrado hoy el éxito al ver a esta mujer semejante a Zri, la amada por todo el mundo, que es como la luna llena, de pechos delicados y redondos, reina que con su resplandor ilumina todas las regiones, de ojos de loto, grandes y graciosos, semejante a Rati, la esposa de Manmattha; la veo ahora como si hubiera sido arrancada del lago de los vidarbhas por culpa del destino, cubiertos los miembros de suciedad y barro como un loto arrancado, parecida a un plenilunio con la luna devorada por Rahu, llena de dolor por su esposo, miserable, como un río de agua al que se le ha secado la corriente, como un loto con las hojas arrancadas o una ave temblorosa, como un lago de lotos de agua turbia, revuelta por las trompas de los elefantes; la veo delicada, con los miembros llenos de nobleza, acostumbrada a un palacio lleno de perlas, como quemada por el sol, como un loto arrancado, dotada de belleza, nobleza y virtud, digna de joyas sin joyas, como la luna el primer día del cuarto creciente en cielo cubierto de negras nubes... (p.p.98-99)

Esta larga descripción predominan los epítetos pero también, las partes del cuerpo que la definen como mujer, comparada con los lotos, con el agua, llenos de suciedad, la riqueza en la pobreza de su abandono. En fin, esta larga descripción que continúa después es la antesala del dolor vivido y de la buena noticia sobre sus hijos y padres. Esta descripción aparentemente innecesaria causa interés en la madre del rey y el mismo rey de Cedi, quienes se acercan para conocer su historia.

\section{El encuentro}

En el capítulo XVII, es el capítulo de los descubrimientos, el brahmán enviado por Bhima, le explica al rey donde habita Damayanti, cómo la descubrió:
Ella es esa joven que reside en el palacio de tu hijo. No hay una mujer semejante en belleza. La morena tiene un lunar nacido en medio de las cejas; yo lo he visto. Ahora ha desaparecido, pues está cubierto de suciedad, como la luna cubierta por una nube. Hecho señal distintiva para su felicidad fue formado por el creador. La línea naciente de la luna no luce con intensidad cuando está cubierta de nubes; pero la belleza de esta mujer no desaparece aún con el cuerpo cubierto de lodo; aún sin adornos brilla al presentarse igual que el oro. La joven, delatada por su cuerpo y su lunar, es reconocida por mí, la reina, lo mismo que el fuego escondido por el calor (p.101).

El brahmán explica que el lunar en la frente fue hecho por Brahmā el creador, lo mismo que la línea de la cabeza, signos ambos de la mujer casada y que en el ritual hindú el marido utiliza un tinte rojo como señal de que ella ya no es una mujer soltera. Además habla que el cuerpo y el lunar de Damayantī la han delatado. Otra vez, a pesar de la suciedad en su cuerpo, sobresalen las cualidades de la heroína: la belleza y también la fidelidad al esposo reflejada en el lunar de la frente.

Al oír estas palabras del brahmán, la reina-madre y Sunanda el rey, quien le lavó la suciedad y pudieron observar el lunar, en ese instante, fue reconocida. La madre del rey le dice: Eres la hija de mi hermana: te he reconocido por ese lunar. Yo y tu madre somos hijas del magnánimo rey de los dazarnas, de Sudaman, joh bella! Ella fue entregada al rey Bhima, yo a mi vez a Viravahu; yo te vi cuando naciste, en los darzanas, en casa de mi padre (p.102). Así es como es descubierta Damayantī y cómo logra regresar a casa de su padre.

Por su lado el rey Bhima pide que busquen a Nala, y por todos los lugares a los que lleguen deben decir lo siguiente: ¿Adónde te has ido de mi lado, traidor, cortando la mitad de mi vestido, abandonándome dormida, en el bosque, el amado a la amada? (p.103).

\section{Damayanti la heroína}

Después de recibir en palacio a su hija, Bhima ordena buscar a Nala y manda a los brahmanes, a quienes Damayantī les dice que repitan en todas partes las siguientes palabras en 
búsqueda del marido, con ellas le recuerda sus deberes de esposo a Nala:

¿Adónde te has ido de mi lado, traidor, cortando la mitad de mi vestido, abandonándome dormida en el bosque, el amado a la amada? Ella te espera allí sentada como tú le dijiste...Y más adelante dice: "¿por qué tú eres conocedor del deber has olvidado las dos cosas? Siempre eras celebrado como inteligente y notable, siempre eras compasivo y ahora has perdido la compasión, tal vez por la ruina de mi fortuna. Compadécete de mí, tigre humano. Yo misma te he oído antes decir que la humanidad es el primer deber (p.103).

Con las palabras de Damayantī se inicia el regreso del esposo. Un brahmán llega al palacio del rey Rituparna, donde es cochero Vahuka el pseudónimo empleado por Nala, tal como el texto lo describe: Vahuka por nombre, auriga del Indra entre los hombres, feo, de brazos cortos, famoso en conducir velozmente el carro, excelente cocinero. (p.105) El texto describe a un hombre enano, pero con las dos cualidades que le habían dado los dioses cuando se casa con Damayantī.

Nala disfrazado escucha las palabras y llora. Sin embargo, el brahmán regresa y le cuenta esta noticia, lo que hace a Damayantī ofrecerle más riquezas para que regrese con Nala y le repita las siguientes palabras al rey Rituparna: Va a celebrar de nuevo una elección de marido Damayantī, la hija de Bhima, allá van todos los reyes e hijos de reyes. $Y$, según ha sido fijado el tiempo, será mañana; si has de estar presente, ve pronto, domador de enemigos. Al salir el sol elegirá segundo esposo; no se sabe si su marido Nala vive o no. (p.106)

Así el capítulo XVIII se acaba e inicia el XIX, en donde Rituparna el rey de Ayodhya le pide a Vahuka (o Nala) que lo lleve. De camino, Rituparna le enseña la ciencia de los dados, la ciencia de saber contar. De camino hacia el palacio de Bhima, le dice Rituparna que él sabe contar y que tiene la ciencia de los dados, a lo que Nala, como Vahuka, le ofrece enseñarle la ciencia de manejar caballos. Efectivamante, dice el texto:
Al recibir éste la ciencia de los dados, Kali salió de su cuerpo mientras vomitaba largamente por su boca el violento veneno de Karkotaka.

El fuego de la maldición salió del mísero Kali: atormentado por él el rey había estado fuera de sí por mucho tiempo. Kali, entonces, libre del veneno, tomó su forma natural y el rey de los nisadhas, Nala, airado, quiso maldecirle. Kali le habló, lleno de miedo, temblando, haciendo el anjali: "Contén tu ira, señor de hombres, yo te daré una gloria extraordinaria. La madre de Indraseno, airada, me maldijo hace tiempo, cuando fue abandonada por ti, desde entonces viví en ti lleno de tormentos, oh Indra entre los reyes, lleno de dolor, oh invicto, qemado día y noche por el veneno del rey de las serpientes... (p.113)

El texto dice, que Kali estaba invisible mientras hablaba con Nala, y pronto se mete en el vibhitaka, el árbol que por haber acogido a Kali quedó maldito para siempre. Ya Nala libre de Kali va feliz, pero aún faltan cuatro capítulos para el encuentro de la pareja. Sin embargo, Damayantī manda a su sirvienta a que indague, por su lado Nala debe confirmar la fidelidad de su esposa.

Al fin se da el encuentro esperado, ambos se ven uno en la forma física desagradable y ella sucia y con la misma vestimenta como si fuese un asceta del bosque: Tan pronto como el rey Nala vio a Damayanti, invadido por la aflicción y el dolor, sintió sus ojos llenos de lágrimas. Y Damayanti, al ver así a Nala, se llenó de una tristeza profunda, la hermosa. Entonces, cubierta con un traje rojo, enmarañados los cabellos, llena de suciedad y lodo, Damayanti...(p.128)

Al escucharse uno al otro, él le reclama que pensaba casarse con otro. Ante la duda de la fidelidad de Damayantī, ella le explica que lo había elegido, inclusive antes que a los dioses, y que nunca ha habido otro hombre para ella y le dice:

Tocaré tus pies, señor de la tierra, por esta verdad: que no he hecho nada malo ni en mi pensamiento. El que nunca reposa recorre el mundo, testigo de lo que hacen los seres: que me quite la vida si he hecho algo malo. El de rayos penetrantes recorre siempre el universo: que me quite la vida si he hecho algo malo. La luna pasa delante de todos los seres como un testigo: que me quite la vida si he hecho algo malo. 
Estos tres dioses guardan los tres mundos todos: digan la verdad o si no abandónenme hoy.

Cuando ella le habló así, Vayu dijo: "No ha hecho ésta nada malo; Nala, te lo digo en verdad. Nosotros tres hemos contemplado y guardado a ésta durante tres años. Este engaño lo hizo ella por tu causa, oh tú a quien nadie se asemeja: pues nadie recorre en un día cien yojanas sino tú. Has encontrado a la hija de Bhima y ella a ti, señor de la tierra. No lo dudes vuelve a vivir con tu esposa. Mientras así hablaba Vayu, caía una lluvia de flores... (p.129)

Al final del capítulo XXIV, se dice que reinician su vida matrimonial después de pasar la noche juntos, y después de ponerse el vestido que lo transformaba de nuevo en Nala, el texto demuestra la intervención divina para una nueva unión de los esposos. En el último capítulo, Nala juega de nuevo con su hermano y recupera el reino y viven en paz.

\section{Damayanti, un estereotipo de mujer en la épica india}

Se puede considerar a Damayantī un modelo de construcción social, un estereotipo de la mujer ideal: la esposa siempre fiel, aún en la adversidad. A diferencia de la esposa de los Pandavas, Draupadī, Damayantī no se enoja, solo cuando maldice a Kali, después de que Nala la ha abandonado con la mitad del vestido. Sin embargo, ambos son las eternas fieles. Viven el camino de la separación y encuentro. Este intertexto plantea el modelo del matrimonio hindú y de sociedad, el ideal de esposo con sus deberes, lo mismo que el de la esposa, pero la exigencia de la fidelidad es para ella, no tanto para él.

Damayantī escoge al marido por encima de los dioses más importantes. Lo acompaña en el exilio y lo recupera al crear una estratagema que es una mentira, por primera vez, miente ¿por qué lo hace? Acaso es costumbre de las mujeres mentir, esa es la propuesta. Sin embargo, eso no le quita el dharma, porque ha sido fiel. Aplica la ley de que en la guerra y en el amor todo se vale, hasta los dioses lo comprenden.
En cuanto a la figura humana, las descripciones son hiperbólicas, idealizan lo masculino como de lo femenino, especialmente en el momento de la unión. Cuando se separan, ella es la protagonista, cumple el camino del héroe y pasa las pruebas citadas anteriormente, su figura, a pesar del abandono, la suciedad, el miedo, los momentos de locura y dolor, no aplacan su belleza física que la ha caracterizado desde el principio de la obra.

Sin embargo, es necesario comprender que Damayantī es porque también lo es Nala, como héroes los dos en igualdad de condiciones. Así las diferentes descripciones físicas de ambos son la condición necesaria para demostrar que son seres excepcionales y de la casta de los reyes, ksatriyas; además de que el aspecto físico es la prueba de su condición, Damayantī por su lado, nunca pierde su belleza física porque es fiel, ha cumplido con el dharma, la fuerza moral, la verdad; a diferencia de Nala quien es rebajado completamente a un estado de inferioridad a una figura físicamente opuesta a la que tenía: brazos cortos, se convierte en servidor como cochero, en él, se observa que todo ataque contra él es acogido en su cuerpo porque faltó al ritual de la purificación, olvidó el deber religioso.

Sin embargo, Nala al comprender cómo se domina el juego de los dados, comienza su recuperación, vomita a Kali. En cambio Damayantī, al verse desamparada, se abandona ella misma, no realiza los rituales de purificación: no se baña, no se lava los pies, no se peina, ni se lava la cara, y no se cambia del sari partido a la mitad, excepto en el palacio de su padre que se pone un vestido de asceta. Se convierte físicamente en viuda. El regreso y encuentro de ambos implica el encuentro de sus cuerpos también, la transformación de fealdad a belleza, implica una renovación.

El corte del sari, que simboliza la unión matrimonial, ya que ella, al momento de escoger a Nala, lo toca con la punta del sari, primero a los pies luego al hombro, así lo toma completamente y le pone un collar de flores. Pero cuando Nala le corta la mitad del sari y se viste con él, se disfraza de mujer, pierde su virilidad, por eso ella le ayuda a recuperarlo, 
además de que cuando se viste con ropas de hombre su cuerpo se transforma en el hombre bello que ella tanto amaba.

El rey de los Nagas que lo muerde y le inyecta el veneno que tortura a Kali, había sido rescatado por Nala del fuego, un fuego que no lo consume, fuego de asceta, es una ayuda espiritual. Al igual que la ayuda espiritual que le proporcionan los ascetas a Damayantī.

\section{Conclusiones}

El texto transmite cómo la mujer-esposa debe ser fiel si quiere obtener la bendición divina; y que la unión de la pareja se basa en la fidelidad. Y aunque haya una separación, se mantiene la fidelidad de ambos. Y a pesar del deber el mantiene el amor y se renueva la pasión. Ambos cumplen con el Dharma o la ley moral, especialmente Damayantī, ella es la fuerza moral; no pierde su pureza, a pesar de la suciedad, porque sigue siendo fiel, piensa en su esposo todo el tiempo, lo espera y lo busca.

Los dioses intervienen solo para unirlos, pero no se presentan en el destierro. Porque el camino y las pruebas para ambos, las deben pasar por sí mismos. A pesar de la visión de los ascetas que tiene Damayantī, la intervención de los elefantes salvajes y en el caso de Nala con la mordida del rey Naga y su consecuente trasformación, el vestido que lo va a regresar a su estado normal. Son ayudas espirituales no divinas. Sin embargo, quien genera el verdadero encuentro es Damayantī con su astucia, al crear una trampa; lo que expresa como las acciones tienen una consecuencia, esta es la ley del karma.

El camino del héroe Nala es distinto, él sufre tres transformaciones: 1. Nala desnudo y sin status real, vestido con la ropa de mujer. 2. Nala es rebajado de estatura y status social.3. Nala regresa a la figura de hombre guapo y comienza la recuperación de su status, gracias a su fidelidad como esposo.

El encuentro y transformación de ambos, tiene como consecuencia la unión sexual de la pareja, a partir de ésta, se inicia la recuperación del reino, que solo se da como consecuencia de la unión de los esposos, lo que los hace cumplir con el dharma, así queda demostrado que la pareja solo vence obstáculos si cumplen con el primer mandato: la fidelidad, que los dioses confirman cuando Vayu le habla a Nala.

Los dioses solo intervienen para unir la pareja, al inicio, cuando es el cisne que los une, este animal es el vehículo de Brahma el creador, y al final, la naturaleza y los dioses son testigos y sirven de unión.

El Hinduismo, puesto que la obra pertenece a éste, propone las divinidades siempre en parejas, son raras ocasiones en que los dioses no tienen esposa. Se dice que el Hinduismo es el sincretismo entre lo ario y lo preario, el dios y la diosa. La fidelidad y la ausencia de hijos los caracteriza, constituyen así la pareja primordial, en el texto lo que cuenta al final es la unión de los esposos, no el encuentro con los hijos.

En el Hinduismo, con la integración de la diosa, se establece de manera definitiva como la fuerza activa del dios, la Shakti, o energía femenina activa, a diferencia del dios que es la energía pasiva; motivo por el cual, los personajes femeninos de la épica, como Damayantī, quien deja de ser la víctima y llega a ser la heroína de la narración, un modelo a seguir y una representación de la fuerza activa divina y femenina.

\section{Referencias bibliográficas}

Basham, A.L. 1985. The wonder that was India. Macmillan Publishers Ltd., London

1994. A cultural history of India. Oxford University Press, Great Britain.

1989. The origins and development of Classical Hinduism. Oxford at the Clarendon Press, Great Britain

Brodbeck, Simon/ Black, Brian. 2009. Gender and Narrative in the Mahabharata. Routledge, U.S.A. 
Dimock, E.C. 1974. The literatures of India. The University of Chicago Press, Chicago.

Doniger Wendy. 1999. Splitting the Difference. Gender and Myth in Ancient Greece and India. USA: The University of Chicago Press.

Keith, A.B. 1953. A History of Sanskrit Literature. Oxford University Press, London.

MacDonell, A.A. 1979. A practical Sanskrit dictionary, London, Oxford University Press.

McGrath, Kevin.2009. Strī:Women in Epic Mahabharata. Boston, Massachusetts: Ilex Foundation and the Center for Hellenic
Studies, Trustees for Harvard University, Washington, D.C.

Monier-Williams, Sir Arthur. 1960. A sanskritenglish dictionary. Great Britain: Oxford, at the Clarendon Press.

Nala y Damayanti. 1987. Traducción de Francisco Rodríguez Adrados. Madrid: Ediciones Cátedra.

Raman, Sitha Ananthan. 2009. Women in India: a social and cultural history, vol I,II. Santa Bárbara, California.

Pave, Adam. 2006. Rolling the cosmic dice: fate found in the story of Nala and Damayanti. Asian Philosophy, 16(2), 99-109. 